STRUCTURAL BIOLOGY COMMUNICATIONS

ISSN 2053-230X

Received 9 July 2015

Accepted 29 October 2015

Edited by N. Sträter, University of Leipzig, Germany

Keywords: laccase; copper(I) complex; full copper content.

PDB reference: Botrytis aclada laccase, $4 \times 4 \mathrm{k}$

Supporting information: this article has supporting information at journals.iucr.org/f

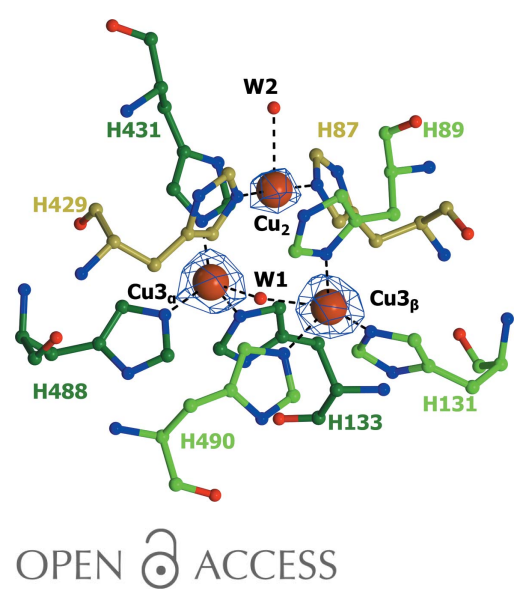

\section{Incorporation of copper ions into crystals of T2 copper-depleted laccase from Botrytis aclada}

\author{
E. M. Osipov, ${ }^{a *}$ K. M. Polyakov, ${ }^{a, b}$ T. V. Tikhonova, ${ }^{a}$ R. Kittl, ${ }^{c}$ P.V. Dorovatovskii, ${ }^{d}$ \\ S. V. Shleev, ${ }^{a, d}$ V. O. Popov ${ }^{a, d}$ and R. Ludwig ${ }^{c}$ \\ aLaboratory of Enzyme Engineering, A. N. Bach Institute of Biochemistry, Leninsky pr. 33, Moscow 119071, \\ Russian Federation, ${ }^{\mathbf{b}}$ Engelhardt Institute of Molecular Biology, Vavilova str. 32, Moscow 119991, Russian Federation, \\ ${ }^{\mathbf{c}}$ Department of Food Science and Technology, BOKU - University of Natural Resources and Life Sciences, Muthgasse 18, \\ 1190 Wien, Austria, and ${ }^{\mathbf{d}}$ RSC 'Kurchatov Institute', Acad. Kurchatov sq. 1, Moscow 123182, Russian Federation. \\ *Correspondence e-mail: e.m.osipov@gmail.com
}

Laccases belong to the class of multicopper oxidases catalyzing the oxidation of phenols accompanied by the reduction of molecular oxygen to water without the formation of hydrogen peroxide. The activity of laccases depends on the number of $\mathrm{Cu}$ atoms per enzyme molecule. The structure of type 2 copper-depleted laccase from Botrytis aclada has been solved previously. With the aim of obtaining the structure of the native form of the enzyme, crystals of the depleted laccase were soaked in $\mathrm{Cu}^{+}$- and $\mathrm{Cu}^{2+}$-containing solutions. Copper ions were found to be incorporated into the active site only when $\mathrm{Cu}^{+}$was used. A comparative analysis of the native and depleted forms of the enzymes was performed.

\section{Introduction}

Laccases (EC 1.10.3.2; benzenediol:oxygen oxidoreductases) belong to the class of multicopper oxidases catalyzing the oxidation of phenols accompanied by the reduction of molecular oxygen to water. Laccases are composed of two or three structurally similar cupredoxin-like domains. These enzymes have been well studied both by biochemical (Baldrian, 2006) and structural (Hakulinen \& Rouvinen, 2015) methods. Owing to their broad substrate specificity and the formation of nontoxic products, laccases are of interest in biotechnology (Xu, 2002).

The active site of laccases comprises four $\mathrm{Cu}$ atoms classified into three types depending on their spectroscopic characteristics (Solomon et al., 1996). The type 1 copper ion can be detected in the ESR spectrum and gives a characteristic absorption at around $600 \mathrm{~nm}$. This ion has a trigonal planar coordination through the $\mathrm{N}^{\varepsilon}$ atoms of two histidines and the $\mathrm{S}$ atom of one cysteine. Type 2 and type 3 copper ions form a T2/T3 cluster responsible for the reduction of molecular oxygen to water. The type 2 copper ion is detected in the ESR spectrum and does not show absorption in the optical region. Two type 3 copper ions are antiferromagnetically coupled through an oxygen-containing ligand and consequently do not exhibit an ESR signal, but show an absorption maximum at around $330 \mathrm{~nm}$. The type 2 copper ion adopts a square-planar coordination geometry with two histidines and one or two oxygen-containing ligands. Each type 3 copper ion is coordinated in a tetrahedral geometry by three histidines and one oxygen-containing ligand, through which it is linked to another type 3 copper ion. 
Table 1

Macromolecule-production information.

Source organism
Forward primer 5BAPml1
Reverse primer 3BAXba1
Expression vector
Expression host
Complete amino-acid sequence
of the construct produced

B. aclada
5'-ATACACGTGCAAGATGAAGTATTTCACAGTC-
TTTACTGC-3'
5'-ATATCTAGACTTAAATTCCAGAATCGTCCTC-
$3^{\prime}$
pPICZB and pPICZ $\alpha$ A
P. pastoris
MKYFTVFTALTALFAQASASAIPAVRSTLTPRQN-
TTASCANSATSRSCWGEYSIDTNWYDVTPTGV-
TREYWLSVENSTITPDGYTRSAMTFNGTVPGP-
AIIADWGDNLIIHVTNNLEHNGTSIHWHGIRQ-
LGSLEYDGVPGTQCPIAPGDTLTYKFQVTQY-
GTTWYSHFSLQYGDGLFGPLIINGPATADYD-
EDVGVIFLQDWAHESVFEIWDTARLGAPPALE-
NTLMNGTNTFDCSASTDPNCVGGGKKFELTFV-
EGTKYRLRLINVGIDSHFEFAIDNHTLTVIAN-
DLVPIVPYTTDTLLIGIGQRYDVIVEANAAAD-
NYWIRGNWGTTCSTNNEAANATGILRYDSSSI-
ANPTSVGTTPRGTCEDEPVASLVPHLALDVGG-
YSLVDEQVSAFTNYFTWTINSSSLLLDWSSP-
TTLKIFNNETIFPTEYNVVALEQTNANEEWVV-
YVIEDLTGFGIWHPIHLHGHDFFIVAQETDVF-
NSDESPAKFNLVNPPRRDVAALPGNGYLAIAF-
KLDNPGSWLLHCHIAWHASEGLAMQFVESQSS-
IAVKMTDTAIFEDTCANWNAYTPTQLFAEDDS-
GI

The activity of laccase preparations depends on the number of $\mathrm{Cu}$ atoms per enzyme molecule. Thus, one way of investigating laccases is to study enzyme preparations in which the copper ions have been partially removed. The type 2 copper ion is more easily removed from the laccase molecule compared with the other copper ions (Malkin et al., 1969). On the one hand, procedures have been developed for the preparation of inactive type 2 copper-depleted forms of the enzyme based on treatment with copper chelators in the presence of reducing agents (Reinhammar \& Oda, 1979; Koroleva et al., 2001). On the other hand, the partial loss of $\mathrm{Cu}$ atoms from the active site can occur spontaneously during the production and storage of laccases.

In some X-ray diffraction structures of laccases which had not been subjected to a copper-chelation procedure, the type 2 copper ion was either absent or had partial occupancy (Glazunova et al., 2015; Ducros et al., 1998; Osipov et al., 2014). The restoration of depleted forms of laccases with a simultaneous increase in their activity is accomplished by treatment of the enzyme with copper salts. The insertion of a type 2 copper ion into fungal, plant and bacterial laccases using $\mathrm{Cu}^{+}$ ions has been described in the literature (Malkin et al., 1969; Reinhammar \& Oda, 1979; Koroleva et al., 2001). The X-ray crystal structure of the fungal type 2 copper-depleted laccase from Coriolopsis caperata showed that a copper ion was inserted into the active site only when $\mathrm{Cu}^{+}$ions were used, whereas the use of $\mathrm{Cu}^{2+}$ ions did not give the desired result (Glazunova et al., 2015). However, it was demonstrated that the incorporation of a type 2 copper ion into the bacterial laccase from Bacillus subtilis occurs in the presence of either $\mathrm{Cu}^{+}$or $\mathrm{Cu}^{2+}$ ions (Durão et al., 2008).

The laccase from the ascomycete Botrytis aclada has previously been isolated and characterized biochemically (Kittl et al., 2012). The structures of this enzyme (hereafter
Table 2

Crystallization.

\begin{tabular}{ll}
\hline Method & Vapour diffusion \\
Plate type & VDX \\
Temperature (K) & 298 \\
Protein concentration $\left(\mathrm{mg} \mathrm{ml}^{-1}\right)$ & 20 \\
Buffer composition of protein solution & $25 \mathrm{mM}$ sodium acetate $\mathrm{pH} 5.0$ \\
Composition of reservoir solution & $1.8 M$ ammonium sulfate \\
Volume and ratio of drop & $2 \mu \mathrm{l}, 1: 1$ \\
Volume of reservoir & $500 \mu \mathrm{l}$ \\
\hline
\end{tabular}

referred to as T2D) and its L499M mutant were determined at $1.7 \AA$ resolution (Osipov et al., 2014). Although the laccase was not subjected to a depletion procedure, the type 2 copper ion was absent in both structures and the residue His429, i.e. one of the two histidines that are involved in the coordination of the type 2 copper ion, points towards $\mathrm{Cu} 3_{\alpha}$.

The aim of the study presented here is to determine the structure of $B$. aclada laccase containing the complete set of copper ions. For this purpose, crystals of the type 2 copperdepleted form of $B$. aclada laccase were soaked in solutions containing $\mathrm{Cu}^{+}$or $\mathrm{Cu}^{2+}$ ions. Restoration of the native form of the enzyme was only observed in the experiment employing $\mathrm{Cu}^{+}$ions.

\section{Materials and methods}

\subsection{Purification and crystallization of laccase}

Laccase from B. aclada (Table 1) was recombinantly expressed in the yeast Pichia pastoris and purified as described by Kittl et al. (2012). Attempts to obtain crystals of the native form of laccase failed. Therefore, the enzyme was deglycosylated (Osipov et al., 2014). The crystallization conditions have been described in detail in a previous study (Osipov et al., 2014). Crystals were grown by the vapourdiffusion technique. A $1.8 \mathrm{M}$ solution of ammonium sulfate in water was used as the reservoir solution. The protein solution consisted of $20 \mathrm{mg} \mathrm{ml}^{-1}$ protein in $25 \mathrm{mM}$ sodium acetate buffer pH 5.0. A $2 \mu \mathrm{l}$ drop composed of equal volumes of the protein and reservoir solutions was used (Table 2). Crystals appeared within $3 \mathrm{~d}$ and reached maximum dimensions of $0.2 \times 0.1 \times 0.05 \mathrm{~mm}$ in one month.

\subsection{Preparation of complexes of $\mathrm{T} 2 \mathrm{D}$ with $\mathrm{Cu}^{+}$and $\mathrm{Cu}^{2+}$}

The complexes were obtained by soaking crystals of the enzyme in reservoir solution containing $0.6 \mathrm{~m} M$ (saturated solution) $\mathrm{CuCl}\left(\mathrm{T} 2 \mathrm{D}+\mathrm{Cu}^{+}\right.$complex) or $10 \mathrm{~m} M \mathrm{CuSO}_{4}$ $\left(\mathrm{T} 2 \mathrm{D}+\mathrm{Cu}^{2+}\right.$ complex). The soaking times were $10 \mathrm{~min}$ and $1 \mathrm{~d}$, respectively.

\subsection{Data collection and processing}

$\mathrm{X}$-ray data sets for $\mathrm{T} 2 \mathrm{D}+\mathrm{Cu}^{+}$and $\mathrm{T} 2 \mathrm{D}+\mathrm{Cu}^{2+}$ were collected on the $\mathrm{K} 4.4 \mathrm{e}$ beamline at the Belok station at the Kurchatov synchrotron-radiation source at $100 \mathrm{~K}$ under a nitrogen flow at a wavelength of $0.98 \AA$ using a Rayonix SX165 detector. Before X-ray data collection, the crystals were placed for $5 \mathrm{~s}$ in reservoir solution supplemented with $20 \%(v / v)$ glycerol. 
Table 3

Data collection and processing.

Values in parentheses are for the outer shell.

\begin{tabular}{lll}
\hline Data set & $\mathrm{T} 2 \mathrm{D}+\mathrm{Cu}^{+}$ & $\mathrm{T} 2 \mathrm{D}+\mathrm{Cu}^{2+}$ \\
\hline Beamline & Beamline K4.4e, Kurchatov SNC \\
Wavelength $(\AA)$ & 0.98 & \\
Temperature $(\mathrm{K})$ & 100 & \\
Detector & Rayonix SX165 CCD & \\
Rotation range per image $\left({ }^{\circ}\right)$ & 1.0 & 119.0 \\
Total rotation range $\left({ }^{\circ}\right)$ & 154.0 & \\
Space group & $C 2$ & $70.1,113.9,80.0$ \\
$a, b, c(\AA)$ & $69.4,113.1,79.6$ & $90,108.8,90$ \\
$\alpha, \beta, \gamma\left({ }^{\circ}\right)$ & $90,109.0,90$ & 0.26 \\
Mosaicity $\left({ }^{\circ}\right)$ & 0.37 & $30-1.83(1.94-1.83)$ \\
Resolution range $(\AA)$ & $30-2.30(2.44-2.30)$ & $124585(16545)$ \\
Total No. of reflections & $81583(12203)$ & $50252(7615)$ \\
No. of unique reflections & $25106(3913)$ & $96.1(90.5)$ \\
Completeness $(\%)$ & $96.7(94.6)$ & $2.5(2.2)$ \\
Multiplicity & $3.3(3.1)$ & $20.8(5.1)$ \\
$\langle I / \sigma(I)\rangle$ & $16.3(2.3)$ & $0.039(0.23)$ \\
$R_{\text {meas }}$ & $0.071(0.60)$ & 24.4 \\
Overall $B$ factor from & 37.7 & \\
$\quad$ Wilson plot $\left(\AA^{2}\right)$ & &
\end{tabular}

The X-ray data sets were processed using the $X D S$ package (Kabsch, 2010a,b). The data-collection statistics are summarized in Table 3.

\subsection{Structure solution and refinement}

The crystals of the complexes were isomorphous to the crystals of T2D. The structures were refined with REFMAC5 (Murshudov et al., 2011). All crystallographic calculations were carried out using the CCP4 suite (Winn et al., 2011). During the refinement of the copper ions with full occupancy, the $F_{\mathrm{o}}-F_{\mathrm{c}}$ difference map contained essential peaks in the region of the copper ions and the $B$ factors of the copper ions exceeded the $B$ factors of the ligands. Therefore, in the final stages of refinement the occupancies of the copper ions were refined manually. Manual correction of the occupancies was followed by $B$-factor refinement. In the final model, the $B$ factors of the copper ions were approximately equal to the $B$ factors of the ligands, and the $F_{\mathrm{o}}-F_{\mathrm{c}}$ difference map did not contain essential peaks in the region of the copper ions. Visual inspection and manual rebuilding of the models was carried out using the Coot interactive graphics program (Emsley et al., 2010). Water molecules were manually added to the structures based on analysis of the difference electron-density maps. The quality of the structures was evaluated with SFCHECK (Vaguine et al., 1999) and PROCHECK (Laskowski et al., 1993). The figures were drawn with CCP4mg (McNicholas et al., 2011). MolProbity (Chen et al., 2010) was used for Ramachandran analysis. Structure-solution and refinement statistics are summarized in Table 4.

\section{Results and discussion}

The structure of $\mathrm{T} 2 \mathrm{D}+\mathrm{Cu}^{2+}$ was solved at $1.8 \AA$ resolution. The crystals of $\mathrm{T} 2 \mathrm{D}+\mathrm{Cu}^{2+}$ have the same qualities as the initial crystals of T2D. Since the structure of T2D $+\mathrm{Cu}^{2+}$ is almost identical to that of T2D, it was not deposited in the PDB.
Table 4

Structure solution and refinement.

Values in parentheses are for the outer shell.

\begin{tabular}{lll}
\hline Data set & $\mathrm{T} 2 \mathrm{D}+\mathrm{Cu}^{+}$ & $\mathrm{T} 2 \mathrm{D}+\mathrm{Cu}^{2+}$ \\
\hline Resolution range $(\AA)$ & $30-2.30(2.44-2.30)$ & $30-1.83(1.94-1.83)$ \\
Completeness (\%) & 97.2 & 96.3 \\
No. of reflections, working set & $23801(1706)$ & $47673(3062)$ \\
No. of reflections, test set & $1292(111)$ & $2579(187)$ \\
Final $R_{\text {cryst }}$ & $0.181(0.278)$ & $0.162(0.241)$ \\
Final $R_{\text {free }}$ & $0.233(0.347)$ & $0.204(0.302)$ \\
No. of non-H atoms & & \\
$\quad$ Protein & 4087 & 4208 \\
$\quad$ Ion & 5 & 3 \\
$\quad$ Water & 155 & 429 \\
Other & 197 & 197 \\
$\quad$ Total & 4444 & 4837 \\
R.m.s. deviations & & \\
$\quad$ Bonds $(\AA)$ & 0.011 & 0.016 \\
$\quad$ Angles $\left({ }^{\circ}\right)$ & 1.62 & 1.92 \\
Average $B$ factors $\left(\AA^{2}\right)$ & & \\
$\quad$ Protein & 38.6 & 23.3 \\
$\quad$ Ion & 38.3 & 21.2 \\
$\quad$ Water & 35.8 & 29.8 \\
$\quad$ Other & 58.9 & 37.7 \\
Ramachandran plot & & 96.8 \\
$\quad$ Favoured $(\%)$ & 96.2 & 3.2 \\
$\quad$ Allowed $(\%)$ & 3.6 & \\
\hline
\end{tabular}

The structures of T2D and $\mathrm{T} 2 \mathrm{D}+\mathrm{Cu}^{2+}$ superimposed with an r.m.s.d. of $0.09 \AA$ using the coordinates of 539 equivalent $\mathrm{C}^{\alpha}$ atoms. Soaking T2D crystals for $24 \mathrm{~h}$ in a solution containing $\mathrm{Cu}^{2+}$ ions at high concentrations did not lead to the insertion of a copper ion into the T2/T3 cluster.

The complexes were obtained using crystals grown in the same drop. During the preparation of the $\mathrm{T} 2 \mathrm{D}+\mathrm{Cu}^{+}$crystals the quality of the crystals visually deteriorated despite the low concentration of $\mathrm{Cu}^{+}$ions and the short period of soaking. The structure of $\mathrm{T} 2 \mathrm{D}+\mathrm{Cu}^{+}$was solved at $2.3 \AA$ resolution. The reduction in the diffraction limit was accompanied by an increase in the mosaicity $\left(0.38^{\circ}\right.$ for the crystals of $\mathrm{T} 2 \mathrm{D}+\mathrm{Cu}^{+}$ versus $0.25^{\circ}$ for the crystals of T2D). Superimposition of the $\mathrm{T} 2 \mathrm{D}+\mathrm{Cu}^{+}$and $\mathrm{T} 2 \mathrm{D}$ structures using the coordinates of 525 equivalent $\mathrm{C}^{\alpha}$ atoms gave an r.m.s.d. of $0.16 \AA$. Residues $1-14$ (the numbering given is according to the T2D structure) and residues 405-408 were not located in the electron-density map for $\mathrm{T} 2 \mathrm{D}+\mathrm{Cu}^{+}$. The latter residues are also not observed in the electron-density maps for T2D and T2D $+\mathrm{Cu}^{2+}$.

The main differences in the structures of $\mathrm{T} 2 \mathrm{D}+\mathrm{Cu}^{+}$and T2D are related to the location of a copper ion in the type 2 site and the orientation of the side chain of His429 (Fig. 1). It should be noted that in the structure of $\mathrm{T} 2 \mathrm{D} \mathrm{Cu} 2$ is completely absent and the sum of occupancies of the copper ions in T2D (2.6) is almost equal to the content of copper ions per molecule for the enzyme in solution as determined by mass spectrometry (Osipov et al., 2014). In the $\mathrm{T} 2 \mathrm{D}+\mathrm{Cu}^{+}$structure the type 2 copper ion has a square-planar coordination formed by the His87 $\mathrm{N}^{\varepsilon}$ and His $429 \mathrm{~N}^{\varepsilon}$ atoms and the $\mathrm{O}$ atom of a water molecule (Table 5). This situation is typical for all laccases containing type 2 copper ions. In the T2D structure His429 is coordinated to $\mathrm{Cu}_{\alpha}$ by the $\mathrm{N}^{\delta}$ atom (Osipov et al., 2014). Thus, the removal of type 2 copper ions could be associated 
with changes in the orientation of the side chain of His429. It should be noted that the occupancy of the type 2 copper ion is lower than the occupancy of the type 3 copper ions. Interatomic distances, $B$ factors and occupancies for copper ions in the T2/T3 cluster and their respective ligands are shown in

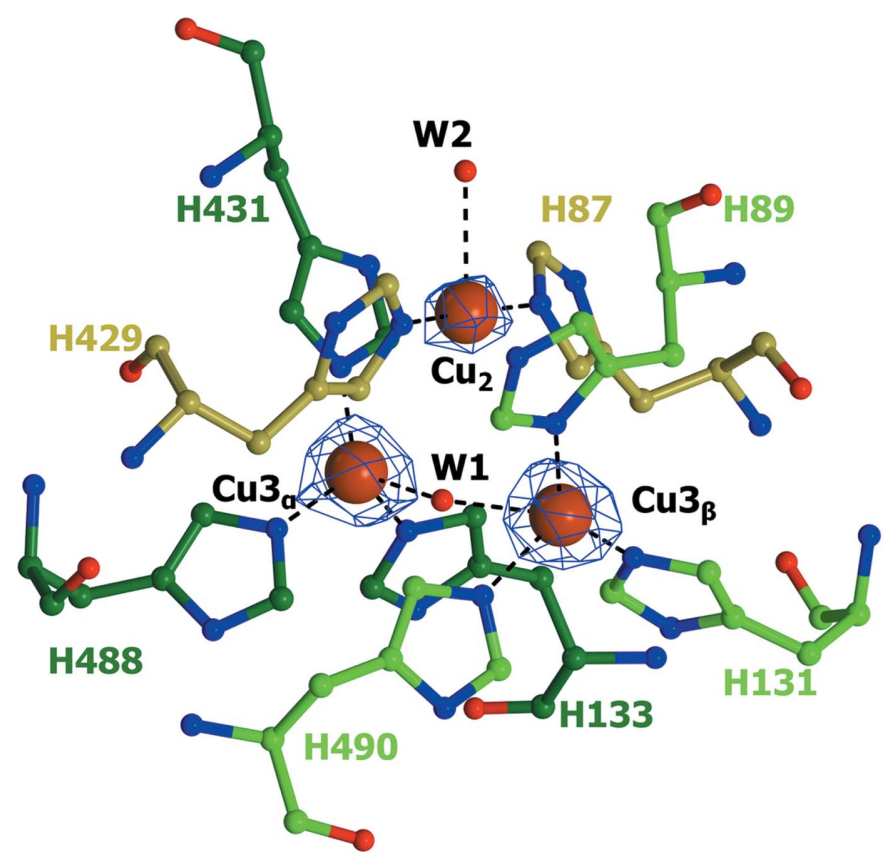

(a)

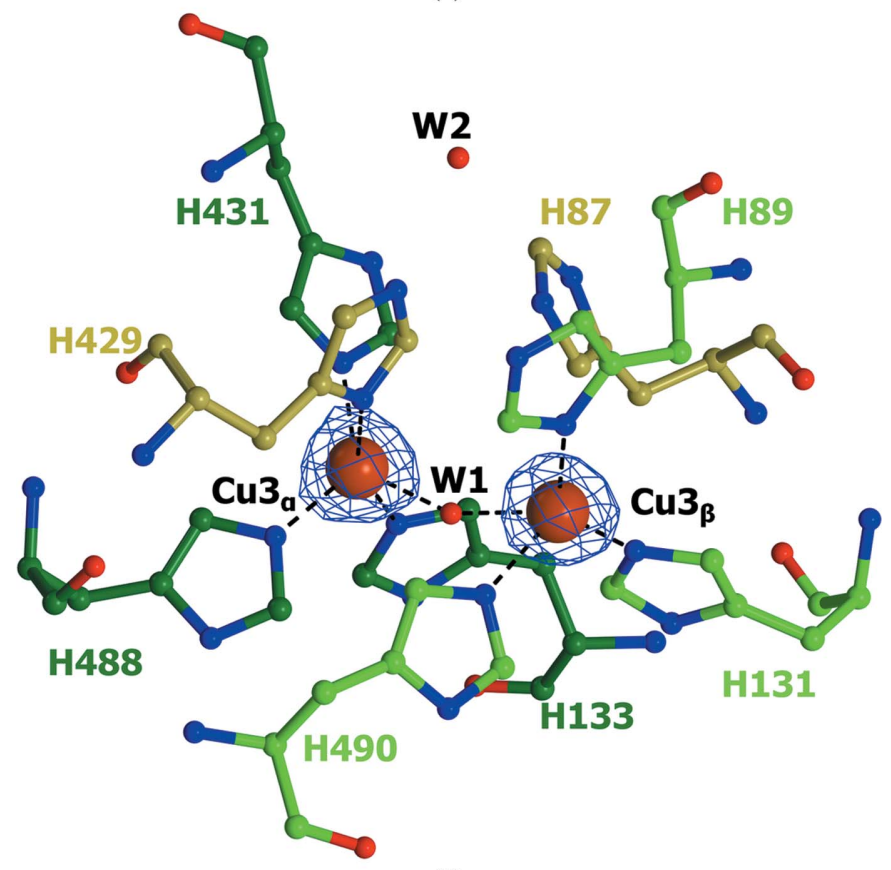

(b)

Figure 1

Structures of the T2/T3 copper sites in $(a) \mathrm{T} 2 \mathrm{D}+\mathrm{Cu}^{+}$and $(b) \mathrm{T} 2 \mathrm{D}$. The amino-acid residues are shown as ball-and-stick models and are coloured according to atom type. The $\mathrm{C}$ atoms of the His residues coordinated to the $\mathrm{Cu}_{\alpha}, \mathrm{Cu}_{\beta}$ and $\mathrm{Cu} 2$ ions are shown in dark green, light green and gold, respectively. The oxygen ligands and copper ions are shown as red and orange spheres, respectively. The $2 F_{\mathrm{o}}-F_{\mathrm{c}}$ electron-density maps (at the $6 \sigma$ level) for copper ions are shown in blue. Coordination bonds are indicated by black dashed lines.
Table 5

Interatomic distances and temperature factors in the T2/T3 clusters of $\mathrm{T} 2 \mathrm{D}+\mathrm{Cu}^{+}$and $\mathrm{T} 2 \mathrm{D}+\mathrm{Cu}^{2+}$.

Occupancies for copper ions are given in parentheses.

\begin{tabular}{|c|c|c|c|c|c|c|c|}
\hline \multirow[b]{3}{*}{$\begin{array}{l}\text { Atom } \\
A\end{array}$} & \multirow[b]{3}{*}{$\begin{array}{l}\text { Atom } \\
B\end{array}$} & \multicolumn{3}{|c|}{$\mathrm{T} 2 \mathrm{D}+\mathrm{Cu}^{+}$} & \multicolumn{3}{|c|}{$\mathrm{T} 2 \mathrm{D}+\mathrm{Cu}^{2+}$} \\
\hline & & \multirow[b]{2}{*}{$\begin{array}{l}A-B \\
\text { distance } \\
(\AA)\end{array}$} & \multicolumn{2}{|c|}{$B$ factor $\left(\AA^{2}\right)$} & \multirow[b]{2}{*}{$\begin{array}{l}A-B \\
\text { distance } \\
(\AA)\end{array}$} & \multicolumn{2}{|c|}{$B$ factor $\left(\AA^{2}\right)$} \\
\hline & & & $\begin{array}{l}\text { Atom } \\
A\end{array}$ & $\begin{array}{l}\text { Atom } \\
B\end{array}$ & & $\begin{array}{l}\text { Atom } \\
A\end{array}$ & $\begin{array}{l}\text { Atom } \\
B\end{array}$ \\
\hline \multirow[t]{6}{*}{$\mathrm{Cu} 3_{\alpha}$} & His $133 \mathrm{~N}^{\varepsilon}$ & 2.06 & \multirow[t]{6}{*}{$34.2(0.8)$} & 31.4 & 2.12 & \multirow[t]{6}{*}{$20.8(0.8)$} & 19.2 \\
\hline & His $431 \mathrm{~N}^{\varepsilon}$ & 1.95 & & 28.3 & 2.04 & & 15.0 \\
\hline & His $488 \mathrm{~N}^{\varepsilon}$ & 1.91 & & 30.4 & 2.03 & & 20.0 \\
\hline & His $429 \mathrm{~N}^{\delta}$ & - & & - & 2.8 & & 24.3 \\
\hline & His $429 \mathrm{C}^{\delta}$ & 3.35 & & 29.5 & - & & - \\
\hline & $\mathrm{W} 1$ & 2.03 & & 26.7 & 1.90 & & 24.5 \\
\hline \multirow[t]{4}{*}{$\mathrm{Cu} 3_{\beta}$} & His89 $\mathrm{N}^{\delta}$ & 2.04 & \multirow[t]{4}{*}{$30.5(0.8)$} & 34.6 & 2.02 & \multirow[t]{4}{*}{$22.7(0.8)$} & 16.0 \\
\hline & His131 $\mathrm{N}^{\varepsilon}$ & 2.01 & & 28.6 & 2.05 & & 19.6 \\
\hline & His $490 \mathrm{~N}^{\varepsilon}$ & 2.10 & & 33.2 & 2.11 & & 18.8 \\
\hline & $\mathrm{W} 1$ & 2.75 & & 26.7 & 2.79 & & 24.5 \\
\hline \multirow[t]{4}{*}{$\mathrm{Cu} 2$} & His87 $\mathrm{N}^{\varepsilon}$ & 1.96 & \multirow[t]{4}{*}{$35.6(0.7)$} & 32.0 & - & - & - \\
\hline & His $429 \mathrm{~N}^{\varepsilon}$ & 1.77 & & 29.9 & - & - & - \\
\hline & $\mathrm{W} 1$ & 3.38 & & 26.7 & - & - & - \\
\hline & W2 & 2.54 & & 35.1 & - & - & - \\
\hline
\end{tabular}

Table 5. The lower occupancy of the type 2 copper ion is also clearly visible in the electron-density map of $\mathrm{T} 2 \mathrm{D}+\mathrm{Cu}^{+}$ (Fig. 1a).

In the structures of $\mathrm{T} 2$ copper-depleted laccases from Coprinus cinereus (Ducros et al., 1998), Coriolopsis gallica (De la Mora et al., 2012) and Trametes hirsuta (Polyakov et al., 2009) a histidine residue equivalent to His429 also forms a weak coordination bond to $\mathrm{Cu} 3_{\alpha}$.

In addition, the electron-density map of the $\mathrm{T} 2 \mathrm{D}+\mathrm{Cu}^{+}$ complex has a peak in the vicinity of His81 at a distance of $2.1 \AA$ from the $\mathrm{N}^{\varepsilon}$ atom. This peak was interpreted as a copper ion with an occupancy of 0.2 .

It should be noted that the incorporation of copper into the $\mathrm{T} 2$ site was unambiguously determined by the X-ray diffraction data. In the study of laccase from $B$. aclada it was shown that the incorporation of a type 2 copper ion only occurs in experiments with $\mathrm{Cu}^{+}$ions. In the case of laccase from C. caperata, reconstitution was also observed only with the use of $\mathrm{Cu}^{+}$salts (Glazunova et al., 2015). Since the active sites of laccases from different organisms have similar structures, it can be suggested that only $\mathrm{Cu}^{+}$ions can be efficiently incorporated into the type 2 copper-depleted active sites of all laccases. This is in good agreement with the fact that $\mathrm{Cu}^{+}$ions are inserted into the type 2 sites of depleted laccases (Malkin et al., 1969; Reinhammar \& Oda, 1979). It has been shown by ESR spectroscopy and kinetic measurements that both $\mathrm{Cu}^{+}$ and $\mathrm{Cu}^{2+}$ ions are inserted into the bacterial laccase from B. subtilis (Durão et al., 2008). However, spectroscopic evidence for the incorporation of copper ions into the enzyme was only presented for $\mathrm{Cu}^{+}$; the kinetic data show that copper ions are more efficiently inserted as $\mathrm{Cu}^{+}$ion into the laccase from B. subtilis.

\section{Acknowledgements}

The authors thank Dr Tatiana Safonova for critical reading, translation and helpful suggestions. The work has been 
financially supported by the Russian Scientific Foundation (project No. 14-24-00172, crystallization and structure solution) and the Austrian Science Fund (FWF, project P25148-B20).

\section{References}

Baldrian, P. (2006). FEMS Microbiol. Rev. 30, 215-242.

Chen, V. B., Arendall, W. B., Headd, J. J., Keedy, D. A., Immormino, R. M., Kapral, G. J., Murray, L. W., Richardson, J. S. \& Richardson, D. C. (2010). Acta Cryst. D66, 12-21.

De la Mora, E., Lovett, J. E., Blanford, C. F., Garman, E. F., Valderrama, B. \& Rudino-Pinera, E. (2012). Acta Cryst. D68, 564-577.

Ducros, V., Brzozowski, A. M., Wilson, K. S., Brown, S. H., Østergaard, P., Schneider, P., Yaver, D. S., Pedersen, A. H. \& Davies, G. J. (1998). Nature Struct. Mol. Biol. 5, 310-316.

Durão, P., Chen, Z., Fernandes, A. T., Hildebrandt, P., Murgida, D. H., Todorovic, S., Pereira, M. M., Melo, E. P. \& Martins, L. O. (2008). J. Biol. Inorg. Chem. 13, 183-193.

Emsley, P., Lohkamp, B., Scott, W. G. \& Cowtan, K. (2010). Acta Cryst. D66, 486-501.

Glazunova, O. A., Polyakov, K. M., Fedorova, T. V., Dorovatovskii, P. V. \& Koroleva, O. V. (2015). Acta Cryst. D71, 854-861.

Hakulinen, N. \& Rouvinen, J. (2015). Cell. Mol. Life Sci. 72, 857-868.

Kabsch, W. (2010a). Acta Cryst. D66, 125-132.

Kabsch, W. (2010b). Acta Cryst. D66, 133-144.
Kittl, R., Mueangtoom, K., Gonaus, C., Khazaneh, S. T., Sygmund, C., Haltrich, D. \& Ludwig, R. (2012). J. Biotechnol. 157, 304-314.

Koroleva, O. V., Stepanova, E. V., Gavrilova, V. P., Biniukov, V. I. \& Pronin, A. M. (2001). Biochemistry, 66, 960-966.

Laskowski, R. A., MacArthur, M. W., Moss, D. S. \& Thornton, J. M. (1993). J. Appl. Cryst. 26, 283-291.

Malkin, R., Malmström, B. G. \& Vänngård, T. (1969). Eur. J. Biochem. 7, 253-259.

McNicholas, S., Potterton, E., Wilson, K. S. \& Noble, M. E. M. (2011). Acta Cryst. D67, 386-394.

Murshudov, G. N., Skubák, P., Lebedev, A. A., Pannu, N. S., Steiner, R. A., Nicholls, R. A., Winn, M. D., Long, F. \& Vagin, A. A. (2011). Acta Cryst. D67, 355-367.

Osipov, E., Polyakov, K., Kittl, R., Shleev, S., Dorovatovsky, P., Tikhonova, T., Hann, S., Ludwig, R. \& Popov, V. (2014). Acta Cryst. D70, 2913-2923.

Polyakov, K. M., Fedorova, T. V., Stepanova, E. V., Cherkashin, E. A., Kurzeev, S. A., Strokopytov, B. V., Lamzin, V. S. \& Koroleva, O. V. (2009). Acta Cryst. D65, 611-617.

Reinhammar, B. \& Oda, Y. (1979). J. Inorg. Biochem. 11, 115-127.

Solomon, E. I., Sundaram, U. M. \& Machonkin, T. E. (1996). Chem. Rev. 96, 2563-2606.

Vaguine, A. A., Richelle, J. \& Wodak, S. J. (1999). Acta Cryst. D55, 191-205.

Winn, M. D. et al. (2011). Acta Cryst. D67, 235-242.

Xu, F. (2002). In Encyclopedia of Bioprocess Technology, edited by M. C. Flickinger \& S. W. Drew. New York: John Wiley \& Sons. doi:10.1002/0471250589.ebt125. 